\title{
UNDERSTANDING THE LEARNER IN THE LANGUAGE LABORATORY
}

Wilga M. Rivers

\section{Abstract:}

Much research and money has been poured into equipment since language laboratories first burst onto the language-learning scene. There was at first great optimism that students would now leam languages with an ease and rapidity never observed in conventional classroom situations. Unfortunately, in many areas students voted against laboratories with yawns and sighs. Technological wonders cannot assist learning without effective courseware, that is, a carefully designed and executed language sequence that provides authentic language materials which are interesting enough to retain the student's attention and encourage perservance. We must understand how students learn languages, appreciate what they need to learn to achieve their objectives in undertaking language learning, and provide materials which bridge the gap between the two.

As we move into the 1980 's, the learning of languages becomes more and more important on the international' (and, frequently, national) scene. We are experiencing the tensions resulting from two opposing trends in modern society: the growing interdependence of nations and peoples, as life becomes more complex and the division of labor more indispensable, and the assertion of individual and affinity group identity, with the demands for self-determination that the pressures of such impersonal interdependence create. It becomes more and more imperative for individuals and groups to understand each other, to be able to communicate with each other, and to respect what others cherish and value. Now, more than ever, we need effective language learning.

Language laboratories have, over the years, bcome language learning laboratories (LLL) or learning centers. To ensure that they are closely integrated with the learning process, I shall use the model of the effectiveness circle of language learning (A), language teaching (B), and instructional personnel (C), with the LLL director (D) at the center. (Sometimes a Language Coordinator works closely with the director and this makes the task less difficult.)

The LLL personnel need to understand findings in language learning and trends in Panguage teaching, in order to help instructors to use the language learning laboratory to facilitate effective language learning by the students. Research in language learning provides insight into the students' task, so that we may find ways of helping them learn more efficiently. Trends in language teaching affect the classroom instruction 
students are experiencing, and determine the expectations of students and instructors alike as to the outcome of the language learning. Course instructors then need the help of knowledgeable and experienced LLL personnel to make the most efficient use of equipment, in ways which are the most pleasurable and advantageous to the students and the most in step with what is known about language learning.

First of all, let us look back for a moment to the early days of the language laboratory, pre-LLL.

Innovative language teachers - the few pioneers-have always been quick to seize new opportunities to bring foreign-language students into contact with authentic speech. Parker tells us that a French conversational course was produced in England on an Edison cylinder as early as 1904, and that this device was soon being tried out with classes at Yale University and elsewhere.' The first fully fledged laboratory was installed at Middlebury College in Vermont in 1929. It had 10 booths, each furnished in a phonograph, a disc cutter, and instruments for work in phonetics. ${ }^{2}$ We must wait till 1945 for the installation of the prototype of the now well-known language laboratory. This 20-booth installation was set up at Louisiana State University by Alfred Hayes. Twelve-inch vinylite discs, recorded at $78 \mathrm{rpm}$, were used, with magnetic headphones, and crystal microphones. ${ }^{3}$ In 1950 this installation, now expanded to 126 positions, was completely converted to magnetic tapes, 12 simultaneous lesson programs being available through a student selector switch."

Technology and innovative enthusiasm had done their part. Now was the time to create the outer circle and relate the newly refined aids to language learning, language teaching, and course objectives.

Since the 1950's were the heyday of habit-formation-through-reinforcement theory in language learning, it was inevitable that the early language laboratory should be seen as the perfect setting for stimulusresponse $(S \mathrm{R})$ learning. Technology and the materials developer provided he $S$ (stimulus) which would automatically bring out the $R$ (response) from the student. Consequently, laboratories all over the world were soon emitting a stream of stimuli, and campuses and schools were filled with the muttering of responses. Correct and relevant responses?no matter. Responses were being heard; they were often recorded, less often checked, and least often rerecorded after further individual instruction. So $S$ R and LL (language laboratory) seemed the perfect partners on the road to linguistic mastery.

For whom? This question was rarely answered. The machine and the instructor knew best. Since little account was taken of the person producing the responses, students began to yawn, and then to tiptoe out, leaving the machines to converse happily with each other. If there was a sign-in/sign-out sheet to check attendance, complaisant friends would look after that. In any case, one could always slip back for a moment, if necessary, after coffee or coke. 
Paralleling the period of development of the language laboratory was a rising time in psychology of interest in what came between the $S$ and the $\mathrm{R}$, namely the $\mathrm{O}$ - the organism: the thinking, feeling, reacting person. In language laboratory terms, this meant the students sitting there in the booths. What did the students want? What was going on in their minds? What were they actually doing in the booths, when they were there? Questions of motivation, perception and cognition, attention, and attention focus came to the fore in psychology and began to interest instructors and language laboratory personnel as well.

By the 1960's, this current of psychological change (which had been long been developing through research in functionalist and dynamic psychology) came to fulf flood in the paradigm switch to cognitive psychology. Language laboratory directors, who had always been closer to the students than materials developers, were quick to identify with this new mood, as evidenced by their selected change of name to language learning laboratory directors - learning by the student being the central element linking the presentation of the language by the instructor and the laboratory practice with it. Thus the change of emphasis from $S R$ to $S O R$ was reflected in the change from $\mathrm{LL}$ to $\mathrm{LLL}$.

The new emphasis on $O$, and the central' $L$, climaxed a period when it had become evident to all concerned with the laboratory that bored, frustrated, and irritated students were bred by tedious, long-drawn-out, mechanical drilling of structural patterns, especially, as so often happened, when these were in a form identical with those the student had already practiced in class and was studying in the textbook. So what's new? wondered the students. Inevitably the news soon spread through school, college, and university that the language laboratory had failed. Funds became harder to get. Why should expensive equipment be replaced if instructors and students were no longer using it, or were using it only reluctantly? If communication was now the goal, how did one communicate with a machine, even a talking machine? Communication is interaction, a give-and-take or a cut-and-thrust; it is something dyadic, for which at least two active, interrelating, reacting persons are essential. It became time to rethink the uses of the language learning laboratory, its role in the language-learning process, and the kinds of materials that could best supplement the active, student-centered approach to language learning which was permeating the classroom. What was needed was ways to motivate students to use the laboratory in the first place and to hold their attention once they were there.

Let us look at some of the findings about language learning which clashed with the prevailing approach of listen and repeat with minimal changes which had determined the form of so many early language Paboratory materials. 


\section{A. Language Learning}

Although no definitive model of language learning has yet emerged, it seems clear that any learning is an active process. Language learners are not passive receptacles that receive and pour out correctly phrased utterances in some automatic fashion. The minds of the students are actively processing all kinds of impressions: filtering out some which they do not consider worthy of attention; readily accepting others which seem imporant to them; creating messages from what they hear, by a process of matching with possible messages, according to their knowledge of the world, the speaker, and the situation; verifying these as the input continues, and switching and changing as they find they are on the wrong track; making errors, correcting these (most often without help), and Pearning from this experience.

Learners in the language laboratory have their own approaches to learning, (strategies or cognitive styles if you willy). No longer should we insist that all students learn through the ear initially, being permitted to see the graphic version only after they have successfully mastered the oral form. We now know that some need a visual support for their learning. We also know that students think and reason before they respond (if material is meaningful, as it should be), and that better learning results if they are allowed time for this. Demand for quick-fire response to develop automatic performance is no longer tenable. Consequently, we must allow the learners to control the rate of presentation as much as possible, with access to mechanisms which permit them to back up and go through an item as many times as necessary before moving on. In fact, many will prefer to take the material away, to work on it in their own time in the way that suits them best. We also realize that some students need to spend more time going over and over the same material than others, who would do better to spend the extra time on other language activities that interest them. Some can concentrate on demanding work for longer periods than others, and, consequently, we must pay much more attention to differences in attention span and memory span when designing learning materials.

Some students, we find, enjoy memorizing and profit from it; others prefer to work everything out step by step, in order to understand exactly what they are doing before they utter a word. Some resist direction of their thinking and effort; others look for structure and teacher guidance. Some prefer to work alone, and, for these, take-home cassettes are the answer. For all, effective language learning is more readily achieved through language exercises which make sense ${ }^{\circ}$ and have some relevance to their interest.7 They respond more readily to activities which challenge them to apply what they know in new contexts, rather than to a monotonous repetition of what they already know, or think they know.

We now recognize that students have different objectives in language learning, and that one diet for all will not meet these personally per- 
ceived goals; we also know that what the students perceive as unrelated to their goals may be cursorily performed, but will not register in any permanent form. Purposeful learning (language learning which results in the performance of some worthwhile acts) will retain attention and establish learned responses more readily than mere verbal participation. Finally, most psychologists agree that perception and production are quite different processes and may well involve quite different grammars. This should bring about a differentiation in the kinds of materials we present for aural comprehension and for production.

We have, then, learned many things about language learning that bring into question quite a few of the time-honored practices which have become identified with language laboratory work: the emphasis on oral production, practiced to a point of automatic response, without the support of a script, and with a very short interval allowed for a rapid response; concentration on details of grammar with a minimal vocabulary, with the expectation that this practice will carry over to lisening comprehension; the structuring of the materials in minimal steps, so that students will not make mistakes; the withholding of explanations until students have reached a certain level of smooth performance on drills and exercises; the lockstep presentation of language laboratory material with unvarying content, standardized pauses, and a relentless forward movement to the end of the tape. With the advance to a language learning laboratory, many of the practices must be rethought and materials redesigned. Whose responsibility will this be?

\section{B. Language Teaching}

Times change. Objectives of students and community change. Approaches to language teaching change to meet new objectives. Language learning laboratory directors must be aware of these changes in class teaching, so that they can help instructors and materials developers to use the resources of the laboratory to their full effect. Language laboratory personnel should be able to advise their colleagues on effective use of media for new methodologies. The laboratory director is the kingpin in days of change, not a mere factotum to carry out routine operations at the direction of others who may not realize the full potential of the laboratory, resource center, or language learning center. Many changes in course approach and teaching techniques have been taking place and the director needs to be aware of these.

1. The order of skill acquisition is by no means a fixed listening, speaker, reading, and writing sequence, with listening and speaking concerning the laboratory, and reading and writing kept for the classroom or for homework. The order advocated by Marcel in the nineteenth century was reading, listening, speaking, writing. Toward the end of the century, reading and writing, with translation, became the initially taught skills, with speaking introduced at a later date, and listening hardly at all. Gouin in the 1890's proposed that one begin with speaking 
accompanied by physical activity, to be supported later by writing; more recently Asher has advocated listening with physical response for a long initial period, and Postovsky has proposed that students begin with listening and writing, with speaking deferred.o In Gattegno's Silent Way, there is very little listening, at least to the teacher or a tape; students begin by trying to create oral utterances after one initial hearing. In Curran's Counseling-Learning/Community Language Learning, students mostly hear each other, as they try to create utterances from prompts from their counselor. In Suggestopaedia, students listen, then read and translate, before they speak.' One can make a good case psychologicalily for listening and reading being learned together, particularly for a specialpurpose course. There is a growing movement not to require students to speak until they are ready. Order of learning skills, then, will depend on objectives and the methodology developed to reach these objectives.

2. There has been a shift of emphasis from what in the past was largely a structural syllabus (the learning of grammatical) structures in the early stages to prepare for fluent oral use of the language) to a functional syllabus based on functions of language (like imparting and finding out factual information; getting things done; socializing); and notions within those functions (such has identifying; suggesting a course of action; or taking leave).10 For the moment, the functional emphasis has been largely an expansion of a narrowly conceived structural syllabus. There has also been a definite swing toward a more experimental syllabus, where students are brought in contact with as much authentic language as possible. Students are encouraged to communicate freely with each other, from the early stages, in situations created within the classroom, in free interaction, or in contacts with native speakers outside the classroom, whether in clubs, local communiy activities, home exchange programs, or short-term study abroad experiences."

Such changes could, and should, mean a considerable change in the types of materials used in the language learning laboratory. Authentic materials, conversations among native speakers in actual situations of the culture, speeches by public personalities, advertisements and soap operas from television programs in countries where the language is spoken are being incorporated more and more into laboratory assignments, and this has means an expansion of use at the intermediate and advanced levels. Authentic interaction, with visible kinesics (body language), and gestures in a setting of the foreign culure become much more accessible through the use of video. Videotapes and videocassettes will be used more and more from the early stages, to facilitate the acquisition and retention of language material by this visually and aurally oriented generation. Songs and popular music enjoyed by the youth of the target culture also help to convey the spirit of the people. The audiovisual laboratory is an indispensable aid in conveying a feeling for the culture, which is an inseparable component of another language. Here the materials developers

NALtD Journal 
and instructors will again need help and guidance from LLL personnel, if they are to prepare effective materials.

No matter what the approach, the audiovisual LLL can make a vital contribution to its success. Students need to be oriented toward the type of learning the instructor is requiring in the course, and this requires close cooperation between instructional staff and laboratory personnel.

\section{The LLL Director and the Instructor}

In many institutions, the LLL Director has to be the expert on language learning and language teaching. Instructors have frequently been trained in literature or linguistics, and take charge of language courses reluctantly, even resentfully. If these instructors have never had close association with laboratory work during their own language studies, they may completely neglect the potential of the laboratory, or use it as a kind of unwelcome necessity. They know it has been paid for and the administration expects it to be used. Native speakers often feel that they themselves provide sufficient authentic speech in their classrooms, and that it is an affront to them to suppose that taped or videotaped material can usefully supplement their work. Some instructors are too preoccupied with their research interests to spend time developing, or even selecting, appropriate laboratory materials, and will expect the laboratory personnel to churn out, in equalized chunks, whatever commercial tapes come with the book, irrespective of their content or quality. A laboratory program out-of-step with or unrelated to the real concerns of the course, leads to frustration, irritation, bewilderment, and absenteeism on the part of the students. If such reaction become apparent, the situation should be discreetly brought to the attention of the instructors, with suggestions for another approach. If the relationship has been cultivated, such proposals will find more ready acceptance. Perhaps there are other materials in the laboratory, about which a new instructor is ignorant-materials which have proven their worth on other occasions. Perhaps the commercial tapes are just too long, the pauses too short, or the practice segments too protracted, with no variety or activity to refresh the student. These things. are easily remedied, and most instructors will welcome help in meeting student objections, which they are surely reaching their ears.

An instructor, naive in the use of media, may benefit from a discussion on what media can do that cannot be accomplished by instructor and textbook alone. Some such list as the following will emerge: facts wellknown to language learning laboratory, personnel, but well worth repeating to new instructors.

The laboratory, properly supplied with carefully designed materials, can provide:

- contact with authentic speech which can be heard and reheard 
without embarrassment to the speaker or the listener, and as often as necessary for comprehension;

- contact with a variety of accents, voices, and dialectal variants;

- opportunity to work at one's own pace, for as long or as short a time as one needs;

- privacy to make mistakes without embarrassment; to practice and repractice problems of pronunciation and production of fluent utterances;

- opportunities for remedial study: makeup work; extra study in areas of one's own weaknesses, repracticed in one's own way according to one's perceived needs (this may include written exercises: dictees, dictocomps, resumes, cloze tests);

- opportunities for supplementary contact with authenic material of value for individual projects, in the language course or another: for listening to plays, commentaries, news broadcasts, literary reading, or music; for vivewing films or television material from a country under study.

The LLL director and the instructor will work out others. The opportunities to help the student learn a language, and learn to use it well, are there. It is for the LLL personnel to make sure that it is not neglected or under-used because of ignorance, timidity, or indifference on the part of instructors. If too many instructors are clearly unaware of the potential of the LLL, a workshop may be he most pressing need. There is nothing like actually manipulating equipment and working with material's oneself to arouse interest and enthusiasm for improving programs in the future. The student is best served when LLL personnel and instructional staff are working closely in harmony.

Computer-assisted instruction, microchips, satellite reception, videodiscs for take-home study-many interesting possibilities are on the horizon. New technologies change nothing without a corresponding development in courseware (the province of the instructor). As long ago as 1964, Hocking observed that "perhaps the most popular and persistent misunderstanding, vaguely felt rather than expressed, is a naive faith in gadgetry-a feeling that push buttons and elecronics can somehow solve all problems."'1s We now know from experience that the major problems lie elsewhere: with the persons who use the laboratory: instructors, students, and, yes, language learning laboratory personnel. It is for the latter to take the lead, to see their role as more than that of maintaining and installing equipment and ensuring the smooth running of laboratory sessions. They must also be leaders in applications of theory to practice to ensure that the second $L$ (learning), having made is way into the name of the laboratory, does not slip away inadvertently, because it is perceived as superfluous.

FLEAT Conference 1981: Japan

Wilga M. Rivers

Harvard University 


\section{NOTES}

1. Model for Second Language Education" (in press), discussed in detail in Stern, 1981.

2. Elton Hocking, Language Laboratory and Language Learning, Washington, D.C.: Department of Audiovisual Instruction, National Education Association of the U.S.A., 1964, p. 11.

3. William Riley Parker, The National Interest in Foreign Languages, Third edition. Washington, D.C.: Government Printing Office, 1962, p. 67.

4. Discussed in W. M. Rivers, "From Linguistic Competence to Communicative Competence," TESOL Quarterly 7 (1973): 25-34.

5. Wilga M. Rivers, Teaching Foreign-Language Skills. 2d ed. (Chicago: University of Chicago Press, 1981), pp. 55-59.

6. Wilga M. Rivers and Bernice J. Melvin, "Language Learners as Individuals: Discovering their Needs, Wants, and Learning Styles," in J. E. Alatis, H. B. Altman, and P. M. Alatis, eds., The Second Language Classroom: Directions for the 1980's (New York: Oxford University Press, 1981), pp. 87-91.

7. An attempt to draw together these three trends has been made by the staff of the Modern Language Centre of the Ontario Institute for the Study of Education. See H. H. Stern, "Communicative Language Teaching and Learning: Toward a Synthesis," in Alatis, Altman, and Alatis, eds., 1981); and J. P. B. Allen, "A Three-Level Curriculum Model for Second Language Education" (in press), discussed in detail in Stern, 1981.

8. The Silent Way, Counseling-Learning/Community Language Learning, and Suggestopaedia are discussed in depth in E. W. Stevick, Teaching Languages: A Way and Ways (Rowley, Mass.: Newbury House, 1980.)

9. For more information, see T. A. van Ek, The Threshold Level for Modem Language Learning in Schools. (London: Longman, 1977. Original publication: Strasbourg: Council of Europe, 1976.) 


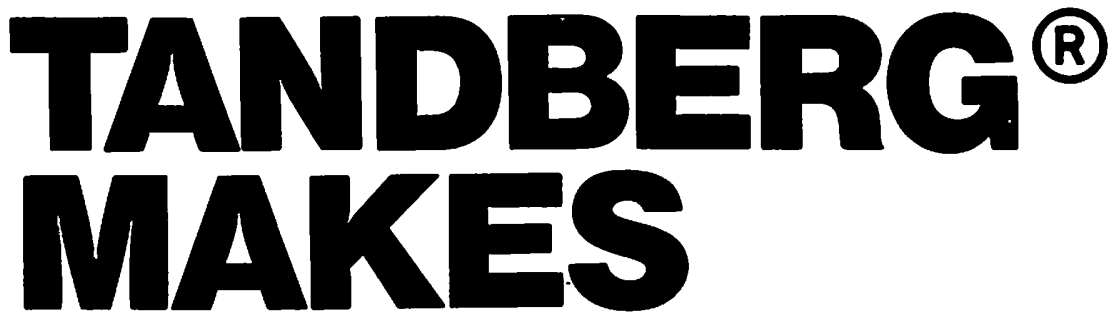

Fremdsprachenlehrhilfentechnologie

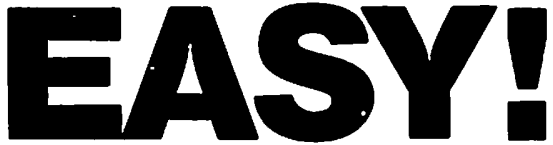

Difficult words become easy with the Tandberg IS 9 Learning Laboratory.

Microprocessor technology has allowed greater freedom and flexibility to produce the most versatile Learning Labs at a reduc-

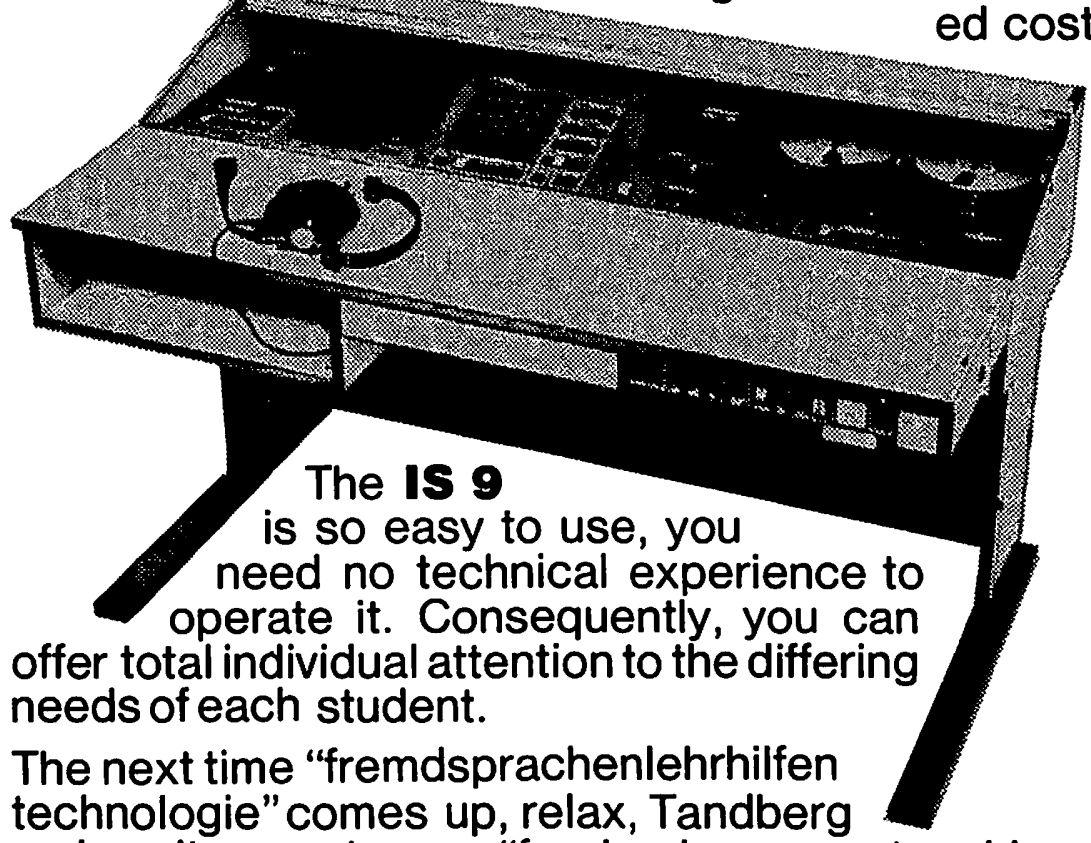
makes it easy to say, "foreign language teaching aids technology."

We've worked hard, so you won't have to. TANDBERG OF AMERICA, INC.

Labriola Court Armonk, New York 10504

(914) 273-9150 